\title{
The Praxis of Social Enterprise and Human Security: An Applied Research Agenda
}

\author{
Malcolm D. Brown \\ School of Arts \& Communication, University of Southern Queensland, Toowoomba, Queensland, Australia; \\ E-Mail: Malcolm.Brown@usq.edu.au; Tel.: +61 746311062; Fax: +61 746311063
}

Submitted: 5 November 2013 | In revised form: 29 January 2014 | Accepted: 3 February 2014 |

Published: 21 February 2014

\begin{abstract}
The growth of social enterprise within development NGO work might lead one to suspect it has been irredeemably corrupted by neo-liberal capitalism. However, using the tools of capitalism is not the same as subscribing to the values of capitalism. This paper is situated at the intersection of five fields: human security, international development, social enterprise, social franchising, and left-wing anti-capitalist thought. It examines the relevance of social enterprise to human security and to development, the relationship between social enterprise and the anti-capitalist values of the left, and it then focuses on social franchising-a subset of social enterprise that highlights the importance of cooperation-suggesting that it may be a useful methodology for NGOs carrying out educational work in parts of the developing world. It synthesises and extends ideas that I have presented elsewhere [1-3], it draws on ethnographic fieldwork on the Thai-Burma border, and it puts forward an agenda for further applied research that is rooted in a sociological analysis of civil society and contributes to the human security paradigm.
\end{abstract}

Keywords: anti-capitalism; human security; international development; left-wing thought; praxis; social enterprise; social franchising

\section{Human Security and Social Enterprise}

There is no commonly agreed definition of social enterprise, but I provisionally define it as a practice which is motivated by the objective of solving social and/or environmental problems, but which uses the tools of capitalism, especially trade, to do so. To begin refining this definition, it is appropriate to identify three distinct social enterprise paradigms, each of which instantiates a broad set of values and, consequently, a particular conceptualisation of the field and its practices: the American approach, which emphasises the role of the entrepreneur; the European approach, which views social enterprise as an evolution of the cooperative; and the Asian approach, the social business paradigm, which is rooted in the work of

(C) 2014 by the authors; licensee Librello, Switzerland. This open access article was published under a Creative Commons Attribution License (http://creativecommons.org/licenses/by/3.0/). 
Muhammad Yunus. The Asian paradigm is noteworthy, because it constitutes an approach to development which has emerged from the developing world itself.

The contributions of Muhammad Yunus and Amartya Sen are especially notable in bridging the fields of social enterprise and human security. Both have contributed to academic discourse and practice within these fields. Yunus's development of microcredit has had a practical impact on the lives of poor people around the world, and has contributed to their human security by improving their economic security; he has also contributed significantly to the theory of social business and social enterprise (e.g. [4]). In Sen's case, not only has he contributed directly to the field of human security as an academic, but he has also contributed to United Nations discourses of human security, human rights, and development. What is more, there is an 'Asianness' to their work that is both appreciable and significant, as it is a developing-world discourse of development and, by extension, of human security.

Yunus's impetus came from observing the lives of the rural poor in Bangladesh, and his model was initially conceptualised as a local response to local circumstances. Yet, it has been applied not only in the developing world, but also to situations of poverty in the United States, continental Europe, Scotland, and Japan, among others ([4] pp. vii-xxiv, 160-162). Similarly, Tadjbakhsh and Chenoy show that Sen's central contributions to the social sciences were made in response to the development needs of the South Asian subcontinent:

Sen's theoretical revolution, in the technical language of 'functionings' and 'capabilities', was in tandem with the practical dictates of Mahbub ul-Haq, the Pakistani planner associated with the foundation of the UNDP Human Development Approach, who posed a simple statement that the purpose of all public policies is to increase people's choices. In his 'Development as Freedom', Sen elaborated on why and how freedom is at the same time the main goal and the main means to achieve development ([5] p. 20).

Tadjbakhsh and Chenoy locate their own perspective within an experience of the developing world and its relations with the West:

...the collaboration brought together one Iranian woman who had been educated in American universities and had worked in the UN before moving to teaching, and an Indian woman steeped in the tradition of activism that, fortunately, does not escape the faith of intellectuals in India ([5] p. 5).

Using the language of 'the South' and 'the North' (broadly equivalent to the 'developing' and 'developed' or 'Westernized' countries of the world), they point to 'the collective experience...of mistrust...with concepts that came from international organizations, which to the South, were often seen as institutions led by powerful Northern nations. Whether it was democracy, human rights and now human security, the discourses smacked of power in the construction of the terms' ([5] p. 4). This does seem like an appreciably Southern paradigm, which elucidates the 'Northernness' of some others.

This is especially apparent when they discuss the notion of 'humanitarian intervention', a particular use of the concept of human security in international politics which has extended the just war theory to one that legitimises war when it is prosecuted for reasons, or pretexts, of human security ([5] pp. 196ff). The lack of intervention in Rwanda in 1994, and the actual intervention in Kosovo in 1999, have both been debated extensively. The Rwandan case has been used to justify subsequent interventions in Kosovo, Iraq, and Libya, for example, although Chomsky has argued that the intervention in Kosovo 'greatly accelerated slaughter and dispossession' ([6] p. 81). Tadjbakhsh and Chenoy observe that 'incidents of selective humanitarian intervention have made much of the South, especially Civil Society, cynical of the concept to the extent of rejecting it' ([5] p. 198). They cite Walden Bello as an example:

...most of us, at least most of us in the global South, recoil at Washington's use of the humanitarian logic to invade Iraq. Most of us would say that even as we condemn any regime's violations of human rights, systematic violation of those rights does not constitute grounds for the violation of national sovereignty through invasion or destabilization. Getting rid of a repressive regime or a dictator is the responsibility of the citizens of a country [7].

Although none of this is conclusive, it is at least suggestive of a distinctively Southern human security paradigm, albeit one that is incomplete, and that has gained limited acceptance in the developing world. The existence of such a paradigm may or may not be interesting in itself, but it is significant in that it allows its proponents to criticise the tendency of some in the South to reject human security in its entirety as a tool of Western neo-imperialism. Tadjbakhsh and Chenoy say that 'the advent of human security should be seen, instead, as the triumph of the South to put development concerns into global security discussions', because 'a human security approach for the South would allow it to shed international light on the concerns of underdevelopment and individual dignity at a time when state-based interests are increasingly being used in the global war against terrorism' ([5] p. 35). And for Mahbub ul-Haq, human security paradigms create the potential for a 'new partnership between the North and the South based on justice not, on charity; on an equitable sharing of global market opportunities, not on aid; on two-way compacts, not one-way transfers; on mutual cooperation, not on unilateral conditionality or confrontation' ([8] p. 5). It is 
my contention that Yunus's social business paradigm is an extension of this distinctly Southern human security paradigm, because it is rooted in an empirical observation of Southern conditions, and premised on an equal intellectual dialogue between North and South.

\section{Social Business}

Yunus distinguishes social business-his preferred term-quite sharply from other phenomena within the social economy ([4] pp. 3-12), which includes social enterprise and social entrepreneurship, cooperatives, corporate social responsibility, social franchising, and some practices of donor-based charity and philanthropy. However, they also have much in common, and Yunus's discussion of social business is a good starting point because of its clarity and applicability.

Yunus identifies seven principles of social business, which, in his words, are 'key characteristics', 'the core of social business', 'a touchstone and a constant reminder of the values that are at the heart of the social business idea' ([4] pp. 2-3). They also define, loosely, the spirit of social enterprise and of the social economy more broadly, including social franchising, which I shall discuss later. They are:

1. The business objective is to overcome poverty, or one or more problems (such as education, health, technology access, and environment) that threaten people and society - not to maximise profit.

2. The company will attain financial and economic sustainability.

3. Investors get back only their investment amount. No dividend is given beyond the return of the original investment.

4. When the investment amount is paid back, profit stays with the company for expansion and improvement.

5. The company will be environmentally conscious.

6. The workforce gets market wage with betterthan-standard working conditions.

7. Do it with joy!!! ([4] p. 3)

Of course, we could not realistically use these seven principles as a simple checklist to determine whether an entity is a social business or not, not least because there are potential conflicts and contradictions between them, especially when social and economic gains become contingent on ecological impoverishment. Furthermore, social business and other phenomena within the social economy are more like different dialects of the same language than different languages. These seven principles reflect the spirit or essential baseline motivations of social business, social enterprise, and other entities within the social economy or third sector, and they apply to all three paradigms that were mentioned at the beginning of this article.

What they point to is an ethos of using the tools of capitalism to solve the human security and environmental problems that have been created and exacerbated most damagingly by capitalism. Even if this is unrealistic, using the tools of capitalism is certainly not the same as subscribing to the values of capitalism. To the extent that social business can be classed as capitalism, it is capitalism with a triple bottom line-people, planet, and profit-with the important proviso that profit itself is a tool, not an end in itself. The search for profit is not the driving force of social business. Social business (at least Type 1 social business [9]) can rather be described as involving business-like management of resources to achieve a social objective. Yunus argues that 'a complete break from the for-profit attitude' is essential to social business ([4] p. 16, added emphasis), though I would also like to emphasise a break from the competitive ethos of capitalism. On that note, Yunus states that a cooperative can be a social business when it is owned by poor people ([4] p. 8)-a Type 2 social business [10]-and it can be further observed that ownership by the poor has always been an intrinsic feature of the cooperative movement, from Robert Owen in industrial-revolution New Lanark to the Fair Trade movement in developing countries and international trade today. Grameen Bank, the microcredit organisation founded in Bangladesh by Yunus himself, has since its foundation been a cooperative as much as it has been a social business.

Importantly, Yunus points out that it is relational networks that have allowed social business and microcredit to exist. Not only do social norms and cooperative ownership ensure a high repayment rate on microloans-far higher than is normal for commercial banks in the West-but the development of civil society has also gone hand in hand with the economic empowerment of the poor. Yunus states:

In the early years of Grameen Bank, strong cultural norms in Bangladesh made it hard for us to attract female borrowers.... Over time, we solved these problems by creating a new, alternative culture for village ladies. We taught thousands to read and write, starting with their names-an incredibly empowering experience for them. Thousands more discovered the power of a shared community with other Grameen borrowers who supported one another. They learned to enjoy coming to the Grameen bank centres for weekly meetings at which they would sing songs, engage in simple exercises, and share stories about their families and the small businesses they had created ([4] pp. 65-66).

Mark Munoz, in his book on international social entrepreneurship, makes a similar point: social entrepreneurs and social enterprises need to build relationships, form alliances and partnerships (especially at a local level), and collaborate with others ([11] pp. 48-49, $70-71,86)$. This is partly because social enterprises and social businesses have a mission to change society, and this mission is compromised if they keep 
the secrets of their success to themselves. It is also because cooperation sometimes makes good business sense. An important area of the social economy is that of social franchising, which will be discussed later, and this is an area in which networks are of fundamental importance, because the success of any franchise operation-social or otherwise-is largely down to its ability to plug franchisees into a network of intellectual property and sociability (see [11] p. 85, [12]), in order to provide a relatively secure income. In this area, there is a congruence of ends and means: it makes good business sense to cooperate with those who might otherwise be regarded as competitors, and cooperation is crucial to the mission of a social enterprise.

\section{The Left and Social Enterprise}

The growth of social enterprise may be a second best to a genuinely left-wing, transformative, radical, socialistic process. Social enterprise has appealed to the right, and to centre-left social democrats, because it emphasises self-help, telling the poor that they should, and can, pull themselves up by their bootstraps. Unsurprisingly, this engenders suspicion on the left. There is a view in left-wing circles that capitalism is beyond redemption and cannot be reformed, that the overthrow of capitalism is what is needed if people's lives are really to be improved, that capitalism needs to be replaced with socialism, and before it can be so replaced it needs to be destroyed.

Whether or not this is indeed the case is beyond the scope of this paper, but there is a danger here of turning left-wing anti-capitalist thought into the opium of the people. We may await the messianic advent of a socialistic order, and even work to hasten the day, but we know it is not going to happen soon. This may be frustrating for many people, but for the poorest people of the world, who cannot patiently await this messianic age, it is quite literally a matter of life and death. Their human security needs to be enhanced, their poverty needs to be alleviated, their real freedoms - to use Sen's language [13]—need to be expanded, and their lives need to be improved. And for them, these things need to be done today. It is an urgent human security imperative.

So the left can-and indeed must-be comfortable with social enterprise, if not for the same reasons as the right and centre-left. Social enterprise is a movement that seeks to make a difference, alleviate poverty, reduce exploitation, empower the poor, promote solidarity, and build community. It seeks a more just allocation of the means of production, distribution, and exchange. These are objectives that reflect the values of all shades of left-wing thought, from nineteenth-century Marxism to present-day environmentalism. Yunus's seven principles embody these values and objectives, apart from the first part of objective 6 , which refers to the paying of market wages. This is, admittedly, an important caveat, but in these principles we see an attack on surplus value, on alienation, on the naked cash nexus, and on the unsustainable expansion of capitalism [14]. If the objectives of social enterprise have appealed to the right, this should be regarded as a victory for the left, because the centre ground has been shifted. It should not dilute the left's commitment to those same objectives.

Left-wing anti-capitalist thought and social enterprise have shared objectives because they share the same roots. They share a family resemblance because they share a family tree. Their common roots are in civil society, voluntary cooperation, and, more recently, in local socialism. Let us briefly examine these in turn.

Firstly, civil society is frequently defined as a 'third sector' of society, after the market and the state, but it is less than satisfactory to define it in terms of what it is not. Michael Waltzer defines civil society as 'the space of uncoerced human association and also the set of relational networks-formed for the sake of family, faith, interest and ideology-that fill this space' ([15] p. 7). It has already been observed in this paper that such relational networks are crucial to the success of social enterprise, including within the sphere of development.

Secondly, and more precisely, the civil society in which social enterprise has its roots is the sphere of voluntary cooperation. Voluntary cooperation plays an important role in the history of socialism, from its origins to the present day, in the form of mutualism, for example, and the cooperative movement, which has already been mentioned. More recently, however, the right has claimed the sphere of voluntary activity for itself. The left needs to reclaim this sphere. The values of the left are the values of the French Revolution-liberty, equality, and fraternity-but the casual observer could today be forgiven for thinking that right wingers believe in liberty, left wingers believe in equality, and centrists believe in fraternity. Yet these values are intertwined, and a left-wing political focus on social enterprise may help to reclaim the sphere of voluntary cooperation, and make its expansion a matter of political consensus.

Thirdly, local solutions to local problems has often been a central characteristic of social enterprise. In the UK, this was initially driven by left-wing local councils who were highly resistant to the agenda of the Thatcher government. According to Jim Chandler:

Although politically a passing phase, local socialism has left a valuable legacy. Economic development was put on the menu of central local authority functions.... Sheffield established the first council sub-committee dedicated to economic redevelopment, while the GLC (Greater London Council) under (Ken) Livingstone created a Greater London Enterprise Board to preferentially fund cooperative business start-ups ([16] p. 249). 
Rory Ridley-Duff and Mike Bull observe 'that wellestablished social enterprise networks (in London, Liverpool and Manchester) surfaced where there were strong community development networks during the 1980s' ([17] p. 46). Once again, we see that left-wing anti-capitalist praxis-in the form of local socialismbelongs to the same family tree as social enterprise.

These three points have an important theoretical consequence, which is important enough to flag briefly. In her introduction to the Scottish Enlightenment thinker Adam Ferguson's Essay on the History of Civil Society, Fania Oz-Salzberger states:

It is difficult to see the moment in time when Ferguson claims that society became 'civil'. In the most important sense, it always was....

The foundations of civil society...are communal bonds and public virtue, which are older than property. Ferguson would not subscribe to Rousseau's famous dictum, in his Discours sur l'inégalité (1755), that the first appropriator of land was 'the real founder of civil society' ([18] p. xviii).

In other words, it would be better to regard civil society-including the social economy-as the 'first sector', rather than follow the conventional ordering of the economy (first sector), the state (second sector), and civil society (third sector) [19]. The state and the economy are the 'superstructure' (to use a word that Marx borrowed from Ferguson) of civil society. They are the sphere of competition for power and economic capital. The social economy-social business, social enterprise, social entrepreneurship, cooperatives, etc.is part of the infrastructure. It is the sphere of cooperation, not competition, leading to the accumulation of social capital and the enhancement of human security.

\section{Social Franchising: The State of the Art and Proposals for Future Research}

We now turn to social franchising, which is a subset of social enterprise. Commercial franchising is a form of capitalism that demands an unusually high degree of cooperation between people who might otherwise be competitors, and, as has already been pointed out, cooperation is also intrinsic to social enterprise. So the cooperation that is a part of civil society is especially relevant to social franchising, which is why I treat it as a case study in all of the fields that intersect in this paper.

As well as the practice-based resources on social franchising [20], there is a small but growing academic literature on the subject. It was defined by Dominic Montagu as early as 2002 as 'a franchise system, usually run by a non-governmental organization, which uses the structure of a commercial franchise to achieve social goals' ([21] p. 129). There is an annotated bibliography ('scoping review') on the subject published in the UK [22], and the concept is occasionally mentioned in the more general academic literature on social enterprise and social business (including by Yunus and
Munoz). While (perhaps ironically) the concept has not been standardised in detail, and Montagu's definition is open to multiple interpretations, it is a way of using a specific tool of capitalism to address specific social problems.

Social franchising is particularly important to NGO work in healthcare, and has been applied in education in India, Brazil, and South Africa. It allows small NGOs to tap into the benefits of social enterprise and social entrepreneurship, notably their financial sustainability, with donations or investments being recycled rather than spent. As with commercial franchising, social franchising builds a collaborative framework for small/ medium NGOs to learn lessons from each other, avoid mistakes that have already been made, and achieve economies of scale while retaining the benefits of being small and responsive to community need and participation. Therefore, small NGOs, working together, can have a greater impact due to better deployment of available resources. Social franchising draws on commercial franchising expertise, and provides the advantages of a common brand, including quality assurance for small and large donors. Craig Dearden-Phillips points out that social franchising is particularly suitable for three types of social enterprises: those that are easily replicable, those where a well-known brand matters, and those that need to reach 'critical mass' to succeed ([23] pp. 142-143, 148). These criteria all apply to educational programs run by small-medium NGOs in Southeast Asia, and it is to that subject that we now turn.

A great deal of primary education for refugee children in Southeast Asia, for example on the ThaiBurma border, is provided by small-medium NGOs, though this is impossible to quantify with any precision for various reasons, not least the unknown numbers of refugees and stateless persons of all ages. There are, however, projects aimed at rectifying this. Another reason is the frequent movement of refugees and their families, and this, combined with the absence of a common curriculum in NGO-run schools, creates difficulties for poor refugee children in obtaining a consistent education in which each level of learning is built on a prior level [24]. This is a shortcoming that social franchising can help to address, because standardisation-of pedagogy, curriculum, materials, governance-is an inherent part of social franchising. Informal social franchising has already enabled some NGOs to lower the cost of their educational work, e.g. between 2004 and 2012 Khom Loy Development in Mae Sot, Thailand, lowered the cost of opening a new classroom from US $\$ 3,000$ to under $\$ 500$, and they aim to reduce the cost still further, to $\$ 200$ per classroom.

Standards of teaching in NGO schools are very uneven. Raising standards and building capacity among teachers and volunteers requires inter alia: cost effective, sound, replicable methodologies and models; knowledge sharing networks and communities of practice; communication technology in some cases; 
and strategic standardisation of pedagogy, curricula, materials, and governance. It is important to balance standardisation with cultural relevance and local negotiation, and this is something that social franchising is able to reflect, also thereby contributing to cultural safety (see [25]). In my own fieldwork experience, teachers in NGO schools are often from the same ethnic group as the pupils. This, it seems to me, constitutes good practice in terms of cultural safety, because such teachers are less likely 'to blame the victims of historical processes for their current plights' ([25] p. 18). In Winston Mak's words: 'social franchising allows residents to retain local democratic control of community services' [26].

Montessori schooling has shown some strengths in this regard; however, this needs to be evaluated further and compared with other educational systems. Within the context applied research on social franchising in NGO education in Southeast Asia, such a comparative evaluation would have as its purpose the development of robust, replicable social franchise methodologies that enable relevant NGOs to deliver quality 'good practice' primary education to the poorest children. More precisely, this would involve the examination of actual work in social franchising, and in commercial educational franchising in the West, it would develop best practice principles for social franchising in educational NGO work, and identify in partnership with local communities and NGOs ways in which social franchising can be expanded to help achieve the millennium development goal of universal primary education. It would have the practical benefit of focusing resource deployment away from foundational program development, and towards delivery. I will expand on this shortly.

This would constitute an extension of my own research on NGO cooperation $[1,3]$, a topic that has been identified by the Australian government as important to development. This research has been of interest to some NGOs in Northern Thailand (Blood Foundation, Fortune, other members of the Fang Valley Development Network, and Bring The Elephant Home). It has described different levels (or dimensions) of cooperation between small NGOs: national (through a peak body like the Cooperation Committee for Cambodia (CCC)), local, as part of a network of formal and informal relationships, and within a single NGO that operates as a cooperative. A franchise network is not based on voluntary cooperation to the same degree, but it is another dimension of NGO cooperation, and it has the potential to enhance NGO cooperation within Southeast Asian nation states and internationally within the region (a goal of the CCC).

Research on social franchising in educational NGO work would have significant economic, environmental, social, and human security benefits. Educational attainment levels are directly linked both to economic development, and, more importantly, to beneficial social outcomes. Development in Western countries has been strongly linked to the development of national education systems and free, compulsory education. In a knowledge economy, investments in education pay off in higher quality, more knowledgeintensive jobs, as illustrated by India's increasing competitiveness in the global economy, together with a growing middle class that is highly oriented towards progress. Similar evolutions are under way in many African nations, such as Nigeria and Kenya. Wider access to education has profound social effects, including lower birth rates and greater gender equity.

Research on social franchising in educational NGO work would have significant economic, environmental, social, and human security benefits. Educational attainment levels are directly linked both to economic development, and, more importantly, to beneficial social outcomes. Development in Western countries has been strongly linked to the development of national education systems and free, compulsory education. In a knowledge economy, investments in education pay off in higher quality, more knowledgeintensive jobs, as illustrated by India's increasing competitiveness in the global economy, together with a growing middle class that is highly oriented towards progress. Similar evolutions are underway in many African nations, such as Nigeria and Kenya. Wider access to education has profound social effects, including lower birth rates and greater gender equity.

The development of social franchise methodologies could deliver significant benefit to NGOs and optimisation of their resources in the following ways: training other organisations; benchmarking, selection and evaluation of franchisees to ensure delivery quality, integrity, mission-focus, and standards; and the development of long-term strategies to ensure financial viability and security (which can otherwise be threatened by changing donor priorities). Such research would also contribute to the Millennium Development Goal (MDG) of universal primary education. The MDGs come with measurable indicators; however, refugees and stateless peoples often slip through the net because their numbers are unknown and their existence is not always recognised. This research agenda addresses some of the Istanbul Principles and Siem Reap Consensus on CSO Development Effectiveness, including human rights (the right to education), gender equity, transparency and accountability, and sustainable change with an engaged private sector. Furthermore, it would turn these into long-term human security benefits through the sustainability that is a part of social enterprise, and through in-country capacity building.

Thus, the equal dialogue between North and South that is an intrinsic foundation of Yunus's social business paradigm (and of Sen's capabilities approach) is instantiated in a participatory approach to development and capacity building. Furthermore, the approach outlined here synthesises the Asian and the European paradigms of social enterprise. Consequently, if further 
research in this field is to make a significant contribution to human security, it must involve collaboration between researchers from the global North and the global South, and the process of capacity building must extend well beyond primary education and into research itself.

\section{Conclusion}

In short, this is a paper about praxis, the unity of theory and practice. The theoretical critique of global capitalism, which is a foundation of left-wing politics, is unified with the practice of social enterprise, and, more specifically, of social franchising within a development context. Not only is social franchising a subset of social

\section{References and Notes}

1. Brown MD. The Multi-Faith Ethic and the Spirit of Social Business: Notes from an Ethnography. The Journal of Social Business. 2012;2(1):7-25.

2. Brown MD. Conflicting Perspectives. In: Lautensach AK, Lautensach SW, editors. Human Security in World Affairs: Problems and Opportunities. Vienna, Austria: Caesarpress; 2013. pp. 35-56.

3. Brown MD. Levels of NGO Cooperation and their Empirical Importance. Development Bulletin. 2013;75:102-105.

4. Yunus $M$, editor. Building Social Business. New York, NY, USA: Public Affairs; 2010.

5. Tadjbakhsh S, Chenoy A, editors. Human Security: Concepts and Implications. London, UK and New York, NY, USA: Routledge; 2007.

6. Chomsky N, editor. The New Military Humanism: Lessons from Kosovo. Monroe, ME, USA: Common Courage Press; 1999.

7. Bello W. Humanitarian Intervention: Evolution of a Dangerous Doctrine. Speech delivered at the conference on Globalization, War, and Intervention, International Physicians for the Prevention of Nuclear War, Frankfurt, Germany, 14 January 2006. Revised version available at http://www.tni.org/es/archives/ act/636 (accessed on 3 February 2014).

8. Ul-Haq M. Human Rights, Security and Governance. Peace and Policy: Journal of the Toda Institute for Global Peace and Policy Research. 1998;3(2):3-11.

9. A Type 1 social business is 'a non-loss, nondividend company devoted to solving a social problem and owned by investors who reinvest all profits in expanding and improving the business' ([4] p. 1).

10. '...a profit-making company owned by poor people, either directly or through a trust that is dedicated to a predefined social cause' $([4]$, p. 2).

11. Munoz JM, editor. International Social Entrepreneurship: Pathways to Personal and Corporate Impact. New York, NY, USA: Business Expert Press; 2010.

12. Franchising. Strengthen, Sustain, Support. enterprise; it also instantiates the ethos of cooperation that is constitutive of civil society. Social franchising in a development context-such as educational NGO work in Southeast Asia-is something that can be promoted in neo-liberal terms, and carried out by people with neo-liberal beliefs and a neo-liberal agenda. Nevertheless, its methodology-summarised in Yunus's seven principles-and its raison d'être of social justice mean that, in concrete terms, this is a field in which research and practice can also be supported by academics and practitioners who have a more left-wing political orientation. The expansion of civil society, cooperation, social franchising, and social enterprise more generally, can become a matter of political consensus, and a contributor to human security [27].

Franchising. 2010;23(5):34-39.

13. Sen A, editor. Development as Freedom. Oxford, UK: Oxford University Press; 2001.

14. Sustainability has not always been part of a left-wing platform, but, given what we know today, I would question the left-wing credentials of someone who rejects or ignores the need for ecological sustainability. Of course, this is an analytical rather than a synthetic judgement; that is, it is a matter of how we define left-wing thought rather than what we observe in left-wing thought.

15. Waltzer $M$, editor. Towards a Global Civil Society. Providence, MA, USA and Oxford, UK: Berghahn Books; 1995.

16. Chandler J, editor. Explaining Local Government: Local Government in Britain Since 1800. Manchester, UK: Manchester University Press; 2008.

17. Ridley-Duff R, Bull M, editors. Understanding Social Enterprise: Theory and Practice. London, UK: Sage; 2011.

18. Oz-Salzberger F. Introduction. In: Ferguson A, editor. An Essay on the History of Civil Society. Cambridge, UK: Cambridge University Press; 1995.

19. There is a tendency in the American literature to refer to social enterprise/entrepreneurship as a fourth sector, confining the term 'third sector' to purely non-profit entities. However, this distinction seems overly legalistic within the context of the European and Asian paradigms, which emphasise motivation over process.

20. See especially the website of the Londonbased International Centre for Social Franchising www.the-icsf.org (accessed on 3 February 20014).

21. Montagu D. Franchising of health services in developing countries. Health Policy and Planning. 2002;17(2):121-130.

22. Koehlmoos T, Gazi R, Hossain S, Rashid M, editors. Social Franchising Evaluations: A Scoping Review. London, UK: EPPI-Centre, Social Science Research Unit, Institute of Education, University of London; 2011.

23. Dearden-Phillips C, editor. Your Chance to Change the World: The No-Fibbing Guide to Social 
Entrepreurship. London, UK: Directory of Social Change; 2008.

24. I have avoided any reference to pedagogic jargon such as 'scaffolding' or 'sequential learning' here, because we are talking about very low-cost education in which it is unrealistic to expect teachers to have much training in or knowledge of such pedagogy. The whole point of the exercise is to make the best possible use of the extremely limited resources available, practising scaffolding or sequential learning to the best extent possible, but recognising that it will be of a more 'rough-and-ready' type than such pedagogic jargon might imply.

25. Ramsden I. Towards Cultural Safety. In: Cultural Safety in Wepa D, editor. Aotearoa New Zealand. Auckland, New Zealand: Pearson Education;
2005. pp. 2-19.

26. Mak W. Social Franchising: A Driver for a Better Economy. Available from: http://www.respublica. org.uk/item/Driving-Britain-to-Popular-Capitalism-with -the-Social-Franchising-Co-operative-Model (accessed on 19 October 2013).

27. Numerous academic colleagues have discussed with me the ideas that have gone into this article, and I am grateful to them all, especially Dr Anna Hayes, who read and commented on a complete draft. I would also like to thank the anonymous reviewers for their comments, and acknowledge financial support from the University of Southern Queensland for the ethnographic research from which this article has drawn. 